The Translation Objective in Automatic Dialogue Interpreting

\author{
Birte Schmitz
}

Technische Universität Berlin 


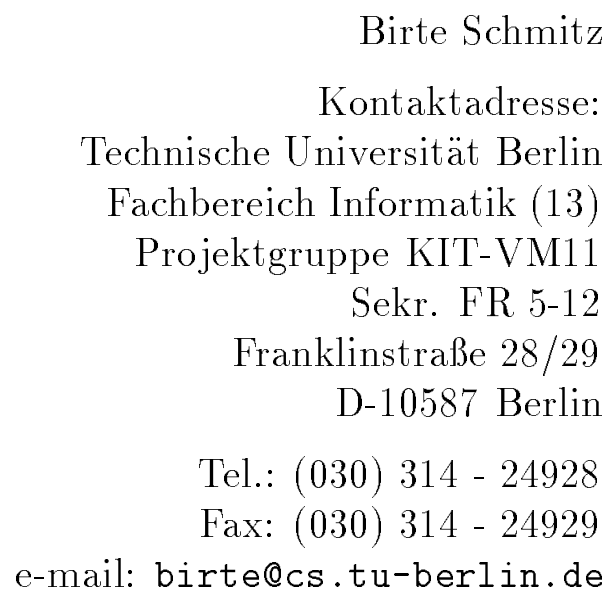

Die vorliegende Arbeit wurde im Rahmen des Verbundvorhabens Verbmobil vom Bundesministerium für Bildung, Wissenschaft, Forschung und Technologie (BMBF) unter dem Förderkennzeichen 01 IV 101 Q 8 gefördert. Die Verantwortung für den Inhalt dieser Arbeit liegt bei dem Autor. 
In C. Hauenschild, S. Heizmann (eds.), Maschine Translation and Translation Theory - Perspectives of Co-operation, Mouton de Gruyter, Berlin, New York, 1997

\title{
The Translation Objective in Automatic Dialogue Interpreting
}

\author{
Birte Schmitz, ${ }^{*}$ \\ Projekt KIT-VM11, FR 5-12, Technische Universität Berlin, \\ Franklinstr. 28/29, D-10587 Berlin, Germany \\ e-mail: birte@cs.tu-berlin.de
}

\section{Introduction}

A fundamental requirement of translation is the determination of the objective of translation. Roughly speaking, the translation objective specifies which aspects of a source-language utterance are to be rendered in a target-language utterance. Especially for the task of automatic dialogue interpreting it is crucial to state a translation objective as word-by-word-translation is pragmatically inadequate. Obviously, many phenomena of performance (like repetitions, false starts, and self-repairs) are to be smoothed out in the interpretation. The question is how to decide on those aspects of the source-language text which are considered as relevant and therefore rendered in the target-language text. A promising answer to this can be found in relevance theory (cf. [Sperber, Wilson 86]) as it explicitly states when an assumption is relevant in a context. According to the relevance principle, the relevance of an assumption in a context depends on its effects on this context and the required effort to process it in this context. For determining a translation objective, the relevance principle must be applied to a concrete translation situation.

Experimental systems in automatic dialogue interpreting are mostly concerned with very limited domains. In this paper, we consider the domain of appointment scheduling. For this restricted domain we specify a translation objective that is represented by dialogue acts.

*This work was funded by the German Federal Ministry of Education, Science, Research and Technology (BMBF) in the framework of the Verbmobil Project under Grant 01 IV $101 \mathrm{Q} 8$. The responsibility for the contents of this study lies with the authors. 
In Section 2 we exploit the term translation equivalence with respect to the definiton of the translation objective. We argue that the translation objective should specify which aspects of the original are to be considered as relevant enough to be preserved in the translation. In Section 3 we introduce relevance theory and show what it contributes to the establishment of a translation objective. Section 4 provides a description of situational factors influencing the translation objective for consecutive interpreting. In Section 5 we describe a dialogue-interpreting scenario: the appoinment-scheduling domain (as defined in the Verbmobil project). For this restricted domain we propose a set of dialogue acts as representations of the translation objective (Section 6). In Section 7 we demonstrate that on the basis of such a formal representation of the translation objective certain phenomena of performance can be smoothed out in the translation. Finally, we sketch our method of automatically determining the dialogue act of an utterance (in Section 8).

\section{Translation as Decision Making}

Translation can be regarded as a decision-making process (cf. [Levý 81]). In this view, a fundamental part of the translation process consists in deciding which pieces of information explicitly or implicitly expressed in the source-language utterance should be expressed in the target-language utterance. We assume that for a concrete translation situation these decisions are guided by a translation objective.

What defines a translation objective? In translation theory there has been a lengthy discussion about the term translation equivalence, which is used to describe the relation between source and target text. The fact that equivalence can be stated with respect to different aspects of the text is illustrated with an example that has been frequently discussed in translation theory ([Levý 81, S.229] or [Gutt 91, S.106]), a part of a poem by Christian Morgenstern, titled "Das ästhetische Wiesel":

$$
\begin{gathered}
\text { Ein Wiesel } \\
\text { saß auf einem Kiesel } \\
\text { inmitten Bachgeriesel. }
\end{gathered}
$$

A rather literal English translation (i.e. expressing equivalence on the denotational level) is presented in [Gutt 91, S.111]):

A weasel

sat on a pebble

in the midst of the ripple of a brook 
In contrast to this translation are five translations by the American translator Max Knight [Levý 81].

1.

A weasel
perched on an easel
within a patch of teasel

3.

$$
\begin{gathered}
\text { A mink } \\
\text { sipping a drink } \\
\text { in a kitchen sink }
\end{gathered}
$$

5.

$$
\begin{gathered}
\text { A lizard } \\
\text { shaking a gizzard } \\
\text { in a blizzard }
\end{gathered}
$$

2.

$$
\begin{gathered}
\text { A ferret } \\
\text { nibbling a carrot } \\
\text { in a garrot }
\end{gathered}
$$

4. A hyena

playing a concertina

in an arena

These translations express equivalence on one characteristic property namely the rhyme and neglect denotational equivalence (only the fact that the conceptual type of the referent is ANIMAL is expressed in all the translations). The example nicely demonstrates that usually equivalence can not be stated on all aspects of a text. Gutt concludes:

...translation and original can be compared with regard to a very large number of factors, any of which can be significant for some detail in the text, and hence needs to be taken into consideration when establishing equivalence. [Gutt 91, S.11]

When relating the concept of translation equivalence to our initial decision problem, two points are relevant to be made:

1. Translation equivalence is a property of source-language and targetlanguage texts, and not of isolated parts of texts. Texts in this sense are characterized by pragmatic aspects such as the situation of their production and the communicative intention of the speaker, by semantic aspects such as coherence, and by formal or structural properties.

2. The term 'translation equivalence' reflects a product-oriented view on translation: it relates the source text on the one hand with the target text on the other but is not concerned with the process of translation.

We suggest defining the translation objective as the operationalized version of translation equivalence. It states for a each utterance of a text which pieces of information are to be rendered in the target-language text. As it is highly dependent on the communicative situation, it seems to be useful to take a general 
theory of communication into account. In the following section we therefore investigate a particular theory of communication with respect to its possible contributions to the definition of a translation objective.

\section{Relevance-Based Translation Theory}

As the process of translation is an act of communication, it follows the rules guiding communication in general. Here we are going to exploit a particular theory of communication, namely relevance theory (cf. [Sperber, Wilson 86]). This theory provides a general principle that can be used as a guidance when making decisions in the translation process. According to this relevance principle "any utterance addressed to someone automatically conveys a presumption of its own relevance" [Wilson, Sperber 88, p.140]. Relevance theory regards communication as inferential. An act of verbal communication is considered to be successful if the communicator produces an utterance from which the audience can infer the interpretation intended by her. These inferences rely both on the stimulus and on certain contextual assumptions that the communicator and her audience hold. The crucial question is how the audience determines which contextual assumptions to actually use in order to infer the intended interpretation. The relevance principle suggests a solution to this problem: The audience knows that the intended interpretation is optimally relevant for them. What does that imply for the context? ${ }^{1}$

An assumption is relevant in a context to the extent that

1. its contextual effects are large

2. the effort required to process it in this context is small.

[Sperber, Wilson 86, p.125]

The audience therefore has to search for a context that on the one hand provides large contextual effects to the potential interpretation. A contextual effect means that either a former weak assumption gets more weight by the interpretation, or it is contradicted by the interpretation and might even be given up. On the other hand, the envisaged context should provide a minimal effort for developing an interpretation for the utterance. This implies that a higher processing effort for the audience must result in larger contextual effects.

\footnotetext{
${ }^{1}$ A problem with relevance theory is that that the introduction of terms like "context" or "processing effort" relies wholly on intuition and is not formally elaborated.
} 
As the relevance principle explains how linguistic structure and contextual knowledge interact, it provides a solution to the general translation problem: which pieces of information explicitly or implicitly given by the source-language utterance should be rendered in the target language, as well as how this information should be expressed. In relevance theory, Sperber and Wilson distinguish two aspects of language use. All figurative uses of language like metonymy or metaphor they call interpretative use of language. The interpretative use is based on resemblance of propositional forms. They define this in the following way in [Wilson, Sperber 88, p.138]: “... Two propositional forms $P$ and $Q(\ldots)$ interpretatively resemble one another in a context $C$ to the extent that they share analytic and contextual implications in the context $C$." When language is used in order to directly describe a state of affairs, Sperber and Wilson call this descriptive use of language. Gutt made use of this distinction in his relevance-based translation theory by describing translation as interlingual interpretive use of language. But in which respects do source-language utterance and target-language utterance resemble each other and how can this be measured? Resemblance is determined by comparing the intended interpretation of the original utterance to the interpretation of the translated utterance that the target-language audience inferred. It is the objective of translation to optimize this resemblance. Gutt writes:

Thus if we ask in what respects the intended interpretation of the translation should resemble the original, the answer is: in respects that make it adequately relevant to the audience - that is, that offer adequate contextual effect; if we ask how the translation should be expressed, the answer is: it should be expressed in such a manner that it yields the intended interpretation without putting the audience to unnecessary processing effort. [Gutt 91, S.101f]

The translator tries to create a translation that has the intended contextual effects and enables the target-language audience to infer these effects without any unnecessary processing effort. The relevance principle is useful insofar as it guides and justifies the decisions a translator has to make. This principle has to be applied to a concrete situation to yield a description of a translation objective. Certain factors influence the actual translation process in a translation situation. In the following section we give a description of factors that characterize a certain set of translation situations, namely consecutive-interpreting situations. 


\section{Factors in Determining an Actual Translation Objective}

In this section we are not concerned with translation in general but with consecutive interpreting. Crucial characteristics are the medium, spoken language as opposed to written language, and the text type, which we confine to dialogues. When determining a translation objective an interpreter has to take at least the following factors into account:

1. the languages involved;

2. the primary dialogue partners, especially

(a) their cognitive environments,

(b) their culture,

(c) their social rank,

(d) their interrelationship;

3. the subject or domain of the dialogue;

4. the type of the dialogue;

5. the physical properties of the actual situation in which the interpreting takes place;

6. the requests of the client who employed the interpreter for this task. ${ }^{2}$

\subsection{The languages}

The languages involved in the interpretation significantly constrain the set of possibilities the interpreter has when deciding what pieces of information explicitly or implicitly given in the source-language utterance should be rendered in the target-language utterance. Each language follows its own norms with respect to the form, the way of expressing contents and the use of certain expressions in standard situations.

Language-specific norms concerning the form of the utterance are reflected by e.g. morphological properties, rules of word order and the way semantic relations are expressed by grammatical relations, as demonstrated in the following examples (cf. [Hawkins 86]):

\footnotetext{
${ }^{2}$ Similar factors are presented in [Prahl et al. 95, p.22].
} 
Mir ist kalt. vs.

I am freezing.

This hotel forbids dogs. vs.

In diesem Hotel sind Hunde verboten.

In many cases, formal properties of a text can only be preserved at the expense of changing the contents, as the Morgenstern-poem above demonstrates.

With respect to contents we think that in general every thought can be expressed in any language, ${ }^{3}$ but has to follow certain language-specific rules or norms. Therefore, in many cases information that is explicitly expressed in the source-language utterance is, according to the rules of the target language, only implicitly expressed in the target-language utterance. The German expression 'die Dolmetscherin' is usually translated into English as 'the interpreter', thereby losing the information that the referent is female. This local loss of information is usually globally accommodated by shifting it to other expressions in the utterance (as in 'The interpreter believes that she has a lot of work to do.'), see also [des Tombes, this volume]. Obviously the reverse case also exists, and an example is the problem to translate the title of a play by Berthold Brecht 'Der gute Mensch von Sezuan' into English (cf. [Levý 81]). The translator has to decide between 'The Good Man of Sechuan' and 'The Good Woman of Sechuan', as English 'person' is stylistically not adequate. In this case the translator has to draw on contextual knowledge in order to decide whether the German 'Mensch' is used to refer to a female or a male person.

Language-specific norms concerning the use of special phrases in certain situations clearly constrain the decisions made by the translator. In standard situations a lot of routine formulas are used. These formulas significantly differ from language to language. Typical examples are greetings like 'How are you' or German 'Grüf Gott' that cannot be translated word-by-word, or warnings like 'wet paint' (the corresponding German phrase is 'frisch gestrichen', literally 'freshly painted').

Although language-specific rules heavily constrain the interpreter's decisions, he has to take into account the actual variation of language use the original speaker chose in her utterance. A language provides the speaker with a whole range of possibilities to express a thought, and according to the principle of relevance the speaker selects that possibility from which the audience can infer the intended interpretation. Therefore the interpreter cannot only rely on his contrastive knowledge of the languages involved but has to take additional factors into account.

\footnotetext{
3This assumption is well known as "effability", cf. [Katz 78].
} 


\subsection{The primary dialogue partners, the domain and the type of the dialogue}

Certain properties of the dialogue partners as well as the domain and the type of the dialogue constitute the register of the text. Following Halliday, [Hatim \& Mason 90] distinguish between two dimensions of language variation. User-related varieties are called dialect, whereas use-related varieties set up the register. The dialect concerns at least social, temporal or social aspects. The register is according to [Hatim \& Mason 90, p.48] determined by three different aspects: field of discourse, mode of discourse and tenor of discourse. Hatim and Mason equate the field of discourse with "the social function of the text (e.g. personal interchange, exposition, etc.)" [Hatim \& Mason 90, p.48]. The mode of discourse refers to the medium of the communication, that is writing vs. speech (cf. [Hatim \& Mason 90, p.49] for a finer-grained distinction of different modes). The tenor of discourse reflects the relationship between the communicators. Hatim and Mason mention distinctions like polite, colloquial and intimate, stressing that they are not discrete categories but establish a continuum.

How do these language varieties influence the general translation objective? The social dialect might be a property of the text that the interpreter decides to preserve in her interpretation. This certainly is problematic, as Hatim and Mason bring to mind:

Yet liaison interpreters working with interlocutors of vastly differing social status (e.g. barrister and accused person) find themselves tempted to neutralise social dialect in translation for the sake of improved mutual comprehension, and to avoid appearing patronising. [Hatim \& Mason 90, p.42]

The register is a crucial factor in determining the translation objective:

- The field of discourse heavily constrains the patterns of language as well as the vocabulary the interpreter can use in her translation.

- The mode of discourse must also be taken into account when determining the translation objective. In contrast to written texts, spoken utterances typically contain linguistic markers expressing hesitation phenomena or repair strategies. It is obviously not adequate to render all these "performance" phenomena word-by-word into the target language, since the hearer might take this as a sign of the interpreter's incompetence.

- The tenor of discourse is something the interpreter obviously has to take into account when determining the translation objective. 


\subsection{Other situational factors}

Other situational factors include the physical properties of the situation in which the interpreting takes place, the client of the translation and the skill of the interpreter.

Physical properties of the situation. Obviously, spoken language in face-toface situations is much more context-dependent than written language. As speaker and hearer are both present in the actual situation, their utterances can be underspecified with respect to those referents present in this situation.

The client. Professional interpreters are usually working on request of a client. He provides the interpreter with certain background information and his special demands. Based on this information the interpreter has to infer a translation objective.

The interpreter. Clearly the interpreter plays a central role in the communicative situation. It is her responsibility to make sure that all factors are accounted for. She has to construct a translation that enables the audience to infer the originally intended interpretation without having any unnecessary processing effort. Her task conveys a typical characteristic of communication in general, namely the necessity to negotiate the meaning. The complexity of her task derives from the fact that she has to negotiate with two partners: one the one hand with the source language communicator in order to make it possible for her to reconstruct the originally intended interpretation, on the other hand with the target-language audience in order to make sure that it actually infers the intended interpretation.

These features characterize the interpreting situation. They clearly have to be taken into account when determining the translation objective. In the following section a concrete interpreting situation will be described with respect to these features.

\section{The Verbmobil Scenario}

Verbmobil [Wahlster 93] is a long-term project funded by the German Federal Ministry of Education, Science, Research and Technology (BMBF). It aims at developing an automatic dialogue interpreting system for spontaneous speech. The underlying scenario for its first phase is restricted to a certain type of negotiation dialogues, namely appointment-scheduling dialogues. This scenario is characterized by the following properties: 
The languages are German, English and Japanese. The language-specific norms regarding the decision which pieces of information to express implicitly versus explicitly are encoded in terms of transfer rules. One example for a significant difference between German and English ist the frequent use of discourse markers in spontaneously spoken German that cannot be expressed in the same way in English:

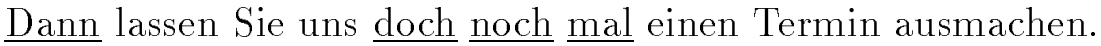
Then let us fix a date.

The subject/domain is confined to appointment scheduling, the dialogue partners primarily focus on potential dates for appointments, i.e. temporal discourse referents.

The field is characterized by cooperative, rather than adversarial interaction. The participants have a well-defined common goal, namely finding a date that suits both of them. They both try to gradually attain their goal.

The tenor: The dialogue partners are supposed to be business partners who are on the same social level. They do not know each other personally and therefore use an intermediate level of politeness.

The physical situation is a face-to-face situation. Most of the dialogue is conducted in English as a common dialogue language. The interpreting system is activated on demand. Therefore parts of the dialogue are monolingual (English), other parts are bilingual with Verbmobil as a mediator.

The interpreting system is a machine. Up to now there are no ways of providing contextual knowledge in general to a machine. This obviously limits the capability of the automatic interpreting system to infer the intended meaning of the source-language utterance. From this point it follows that the task of negotiating the meaning with the primary communicators can hardly be undertaken by a machine. A solution to this problem lies in defining the translation objective. For a scenario as restricted as this, the set of expectable intended interpretations is restricted as well. These intended interpretations represent the translation objective in the process of translation.

In the following section a translation objective for the Verbmobil scenario is introduced. 


\section{The Translation Objective for the Verbmobil Scenario}

In a scenario as restricted as this, the translation objective can be modelled by a pragmatic-oriented abstract type of information that we call dialogue act. Each utterance in a dialogue expresses such a dialogue act. Dialogue acts combine information about an illocution, a propositional content, and a set of prototypical linguistic realizations. They allow us to represent utterances such as

$$
\begin{aligned}
& \text { a. What about Thursday? } \\
& \text { b. I would suggest Thursday. }
\end{aligned}
$$

by the same type, namely a proposal of a date.

For the type of appointment-scheduling dialogues investigated here, we propose the following dialogue acts: ${ }^{4}$

Initialization: The topic of the dialogue, i.e. arranging an appointment, is explicitly introduced. Let's fix a time.

Suggest_Date: A date is proposed. Couldn't we say half past two then?

Reject_Date: A proposed date is rejected. That's not so good.

Accept_Date: A proposed date is accepted. Yes, a quarter to three would suit me fine.

Give_Reason: An explanation for an acceptance, a declination or a proposal of a date is given. I'll still be away in Majorca.

Clarifying-Query: In the morning?

Clarifying_Answer: Yeah.

Request_Comment: The dialogue partner is asked to comment on a proposed date. Would that suit you?

Request_Suggest_Date: The dialogue partner is asked to make a proposal. When would it suit you?

\footnotetext{
${ }^{4}$ The method of determining the set of relevant dialogue acts for a particular scenario is described in [Schmitz, Jekat-Rommel 94], the currently implemented set is presented in [Jekat et al. 95].
} 
These dialogue acts only cover the main topic of the dialogue, namely the appointment scheduling. In addition we have types like greeting, saying goodbye and introducing oneself, confirming the appointment and thanking the dialogue partner for the conversation, which exclusively occur in the opening or closing phases of the dialogue. Note that these dialogue acts can be distinguished into different classes: some of them are purely illocutionary (like greeting or thanking), others contain information about a referent (like proposing a date) or a whole proposition (like giving a reason).

These dialogue acts represent a translation objective for the automatic interpreting of appointment-scheduling dialogues. The interpreting process is performed in two steps:

1. For each utterance its dialogue act is inferred.

2. On the basis of the dialogue act (illocution and propositional content) the generation component produces a target-language utterance.

Table 1 and Table 2 demonstrate that the dialogue acts can actually be used to represent the translation objective.

\section{$7 \quad$ Reducing Traces of the Speaker's Formulating Activities}

Spontaneously spoken language contains "traces of the speaker's work of discourse production" [Gülich, Kotschi 95]. Examples are false starts, hesitation pauses, repetitions, self-repairs, deliberations, or speaker's comments on her formulating activity. These traces should generally not be translated into the target language, as the hearer will be led to interpret them as traces of the interpreter's work of discourse production.

On the basis of the dialogue acts it is possible to establish a translation objective that reduces the speaker's traces of discourse production by encoding rules that either leave out certain redundant information or melt different dialogue acts.

Human interpreters seem to translate according to this objective, as the following example (part of an originally transcribed dialogue, number 31 in [Bade et al.94]) demonstrates (NAD is one of the primary communicators, CHR 
Table 1: Dialogue Acts as Representation of the Translation Objective

\begin{tabular}{|c|c|c|}
\hline Turn & Utterance & Dialogue Act \\
\hline$\overline{\mathrm{A} 1 \_1}$ & $\begin{array}{l}\text { ja, ich würde vorschlagen, wir } \\
\text { legen } z u\langle Z\rangle \text { erst }\langle A\rangle \text { das Treffen in } \\
\text { Stockholm fest, } \\
\text { well, I would suggest, we first fix } \\
\text { the meeting in Stockholm }\end{array}$ & $\begin{array}{l}\text { INIT_DATE and topic: meeting } \\
\text { in Stockholm }\end{array}$ \\
\hline A1_2 & $\begin{array}{l}\langle\mathrm{A}\rangle \text { und zwar }\langle\text { Schmatzen }\rangle\langle\mathrm{A}\rangle \\
\text { würd' ich da gerne }\langle\mathrm{P}\rangle \text { Montag, } \\
\text { den vierzehnten März, }\langle\mathrm{A}\rangle \text { mich } \\
\text { mit Ihnen in Stockholm treffen } \\
\text { in fact I would like to meet you } \\
\text { on Monday the 14th of March in } \\
\text { Stockholm }\end{array}$ & $\begin{array}{l}\text { SUGGEST_SUPPORT_DATE } \\
\text { and date: Monday, the } 14 \text { th of } \\
\text { March }\end{array}$ \\
\hline B1_1 & $\begin{array}{l}\langle:\langle \# \text { Mikrowind }\rangle \text { das würde mir } \\
\text { nicht:〉 passen. } \\
\text { that would not suit me }\end{array}$ & $\begin{array}{l}\text { REJECT_DATE and date: Mon- } \\
\text { day, 14th of March }\end{array}$ \\
\hline B1_2 & 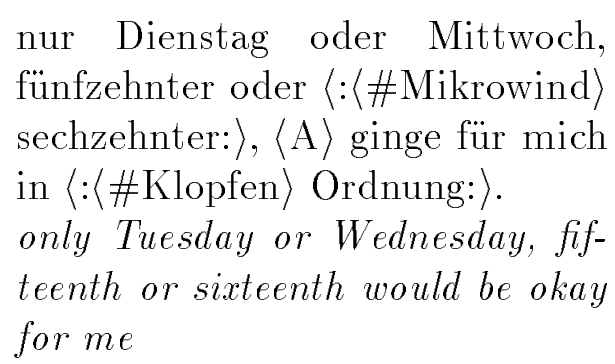 & $\begin{array}{l}\text { SUGGEST_SUPPORT_DATE } \\
\text { and date: Tuesday, 15th of March } \\
\text { and Wednesday, 16th of March }\end{array}$ \\
\hline
\end{tabular}


Table 2: Target-Language Generation Based on Dialogue Acts

\begin{tabular}{|c|c|c|}
\hline Turn & Dialogue Act & Utterance \\
\hline$\overline{\mathrm{A} 1 \_1}$ & $\begin{array}{l}\text { INIT_DATE and topic: meeting } \\
\text { in Stockholm }\end{array}$ & $\begin{array}{l}\text { Let's schedule the meeting in } \\
\text { Stockholm }\end{array}$ \\
\hline $\mathrm{A} 1 \_2$ & $\begin{array}{l}\text { SUGGEST_SUPPORT_DATE } \\
\text { and date: Monday, 14th of March }\end{array}$ & $\begin{array}{l}\text { What about monday, the } 14 \text { th } \\
\text { March }\end{array}$ \\
\hline B1_1 & $\begin{array}{l}\text { REJECT_DATE and date: Mon- } \\
\text { day, 14th of March }\end{array}$ & That does not suit me. \\
\hline $\mathrm{B} 1 \_2$ & $\begin{array}{l}\text { SUGGEST_SUPPORT_DATE } \\
\text { and date: Tuesday, 15th of March } \\
\text { and Wednesday, 16th of March }\end{array}$ & $\begin{array}{l}\text { What about Tuesday the } 15 \text { th or } \\
\text { Wednesday the } 16 \text { th of March }\end{array}$ \\
\hline
\end{tabular}

the interpreter). Note that German 'freitags' is ambiguous; it can either mean 'Friday in general' or it can refer to the Friday mentioned in the previous utterance.

NAD Oh, Moment, ich glaube, Freitag habe ich einen oops one moment I think Friday I have a

festen Termin, da kann ich leider nicht, regular appointment, unfortunately I can't then

also freitags kann ich nicht, so, Friday I can't

ich kann dienstags, mittwochs und donnerstags.

I am free Tuesdays, Wednesdays and Thursdays

Ham Sie da vielleicht noch einen Termin frei?

are you free then?

CHR Friday is impossible but Tuesday, Wednesday, Thursday is okay.

The German dialogue partner NAD declines a previously proposed date, Friday, with three utterances, all expressing the same thing pragmatically. The 


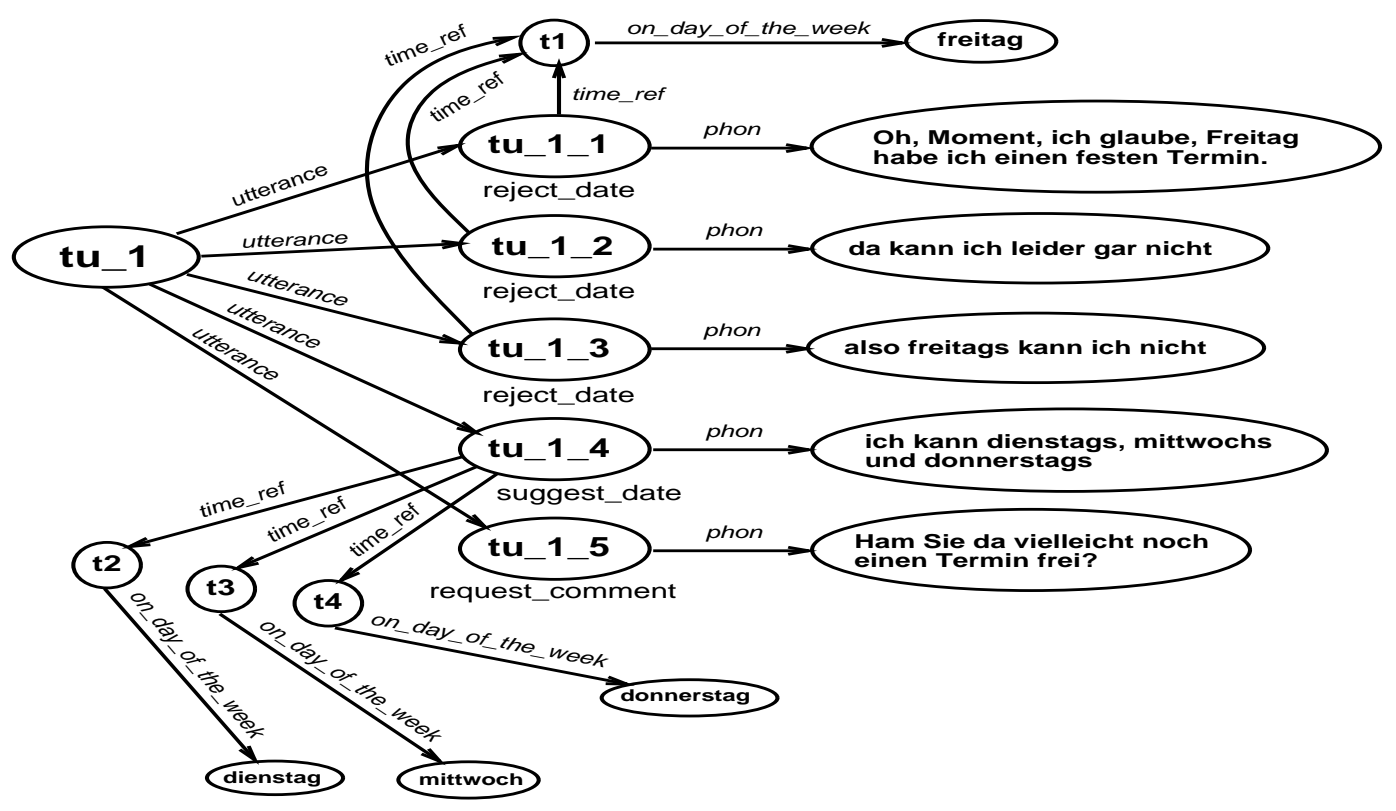

Figure 1: The FLEX representation of the source-language utterance.

interpreter CHR does not render this repetition into the target language, she expresses the declination of the Friday by one single utterance, namely 'Friday is impossible'.

A formal representation can be given, as demonstrated in the Figures 1 and 2 . These figures show the representations of the source language utterance and its interpretation in the Description Logic (DL) system FLEX. ${ }^{5}$ The circled items denote objects, the arrows roles (or two-place-predicates). Both the turns and the utterances they contain are represented as objects. Each utterance-object is connected to representations of its corresponding propositional information and its phonetic realization (the figures only show part of the propositional information, namely the temporal referents). The source-language turn as represented by object 'tu_1' consists of five utterances. The first three utterances all refer to the same temporal referent, namely a Friday, and they all perform the same dialogue act, namely a rejection of the proposed date. According to the translation objective, the information about the dialogue act (Reject_Date) referring to a certain Friday is transferred to the generation component that generates from this information an utterance like 'Friday is impossible.'

\footnotetext{
${ }^{5}$ FLEX [Quantz et al. 96] was developed in the Verbmobil project as an extension of the DL system BACK [Hoppe et al. 93].
} 


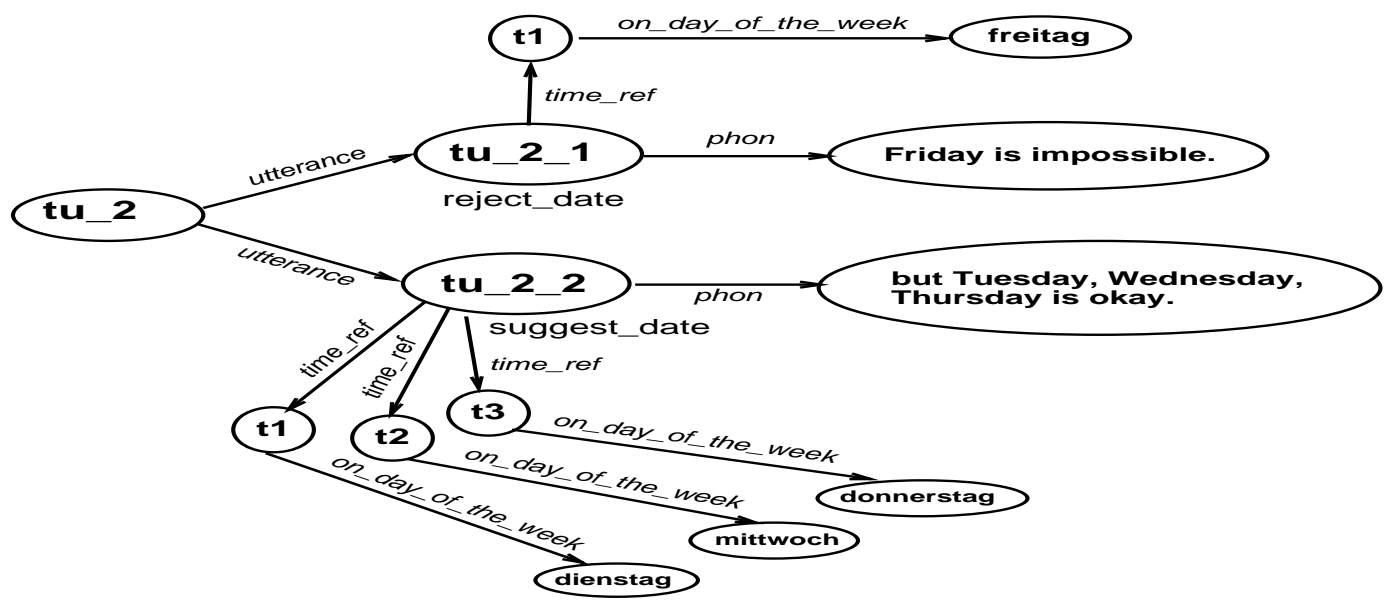

Figure 2: The FLEX representation of the interpreted utterance.

How is the relevant information that constitutes the translation objective, namely the dialogue act of the utterance, determined?

The process of syntactic and semantic analysis introduces (at least) for each non-anaphoric temporal expression its temporal referent. The crucial question is how to determine the illocutionary aspect of an utterance represented by the dialogue act.

\section{Computing the Dialogue Act}

In our approach we exploit all kinds of conventions that allow an utterance to express a certain dialogue act. Thus we use both micro-structural information concerning syntactic, semantic, and pragmatic properties of a single utterance and macro-structural information about the global structure of the dialogue. We encoded these 'conventions' in terms of preference rules and implemented them as weighted defaults in the Description Logic system FLEX.

Given the task to assign a dialogue-act type to an utterance, these weighted defaults have the form:

$$
X \stackrel{w}{\rightarrow} Y
$$

Such a default can be informally paraphrased as follows: if there is a piece of information $X$ in the representation of the utterance, then there is a preference of weight $w$ for the utterance to be of type $Y$. The information represented on the left-hand side of a default concerns different types of knowledge, namely: 
- syntactic information (e.g. sentence type, voice of the verb),

- keywords (certain discourse markers like German 'leider' or 'schon'),

- semantic information (the conceptual content of expressions, the conceptual type of referents),

- macro-structural information (up to now only the dialogue act of the previous utterance).

On the basis of these rules and a partial representation of the utterances, the type of dialogue act for each utterance is inferred. This can be demonstrated with an example. The utterance 5 is represented by the object 2 , as defined in 6.

(5) Wann wäre es Ihnen denn recht? (When does it suit you?)

object_2 :

conc:gut_passen and keyword: whtemp_wann

and satz_typ:int and verb_modus:conj and no(temp_ref)

and previous_dialogue_act:object_1.

On the basis of the following set of default rules the dialogue act request_suggest_date is derived:

$$
\begin{aligned}
& \text { conc:gut_passen } \stackrel{50}{\rightarrow} \text { request_suggest_date } \\
& \text { some(keyword,temporalfrage) and satz_typ:int } \\
& \stackrel{200}{\rightarrow} \text { request_suggest_date } \\
& \text { the(previous_dialogue_act,init) } \stackrel{10}{\sim} \text { request_suggest_date }
\end{aligned}
$$

A more detailed description of this approach and promising results of a first evaluation are presented in [Schmitz, Quantz 95].

\section{Conclusion}

For any kind of translation it is fundamental to state a translation objective. Especially for the task of automatic dialogue interpreting it is indispensable: spoken language typically contains "traces of the speaker's formulating activities". It is obviously not adequate to render all these "traces" word-by-word in the target language. 
For human interpreting in real-world applications, a huge variety of contextual factors influences the translation objective. However, research in automatic dialogue interpreting has started with highly limited domains, where an actual translation objective can easily be determined. The domain itself and the restricted type of dialogue suggest which information is relevant and therefore is to be rendered in the target language utterance.

For the domain of appointment scheduling a certain set of the dialogue acts (i.e. information about the illocution and the propositional content of an utterance) proved to be relevant. For other domains a different set of domain-specific dialogue acts will be applicable. Generally, it seems a reasonable assumption that the rendition of the information provided by the dialogue act is crucial for any domain and dialogue type.

Here we demonstrated how utterances can be automatically classified with respect to their type of dialogue act. We claim that this information combined with information about temporal referents establishes a suitable translation objective. Future work will have to show that from these pieces of information as input, the generation component can actually come up with an output that constitutes an adequate translation.

\section{References}

[Bade et al.94] U. Bade, S. Heizmann, S. Jekat-Rommel, S. Kameyama, D. Krause, I. Maleck, B. Prahl, W. Preuf Wizard-of-Oz-Experimente mit dem VERBMOBIL-Simulator, Verbmobil-Memo 24, Juni 1994

[Gülich, Kotschi 95] Elisabeth Gülich und Thomas Kotschi, "Discourse Production in Oral Communication" in U. Quasthoff (Ed.), Aspects of Oral Communication, de Gruyter, Berlin, New York, 1995, 30-66

[Gutt 91] E.-A. Gutt, Translation and Relevance, Basil Blackwell, Oxford, 1991

[Hatim \& Mason 90] B. Hatim and I. Mason, Discourse and the Translator, Longman, London and New York, 1990

[Hawkins 86] J.A. Hawkins, A Comparative Typology of English and GermanUnifying the Contrasts, Croom Helm, London and Sidney, 1986

[Hoppe et al. 93] T. Hoppe, C. Kindermann, J.J. Quantz, A. Schmiedel, M. Fischer, BACK v5 Tutorial \& Manual, KIT Report 100, Technische Universität Berlin, 1993 
[Jekat et al. 95] S. Jekat, A. Klein, E. Maier, I. Maleck, M. Mast, J.J. Quanz, Dialogue Acts in Verbmobil, Verbmobil-Report 65, DFKI Saarbrücken, 1995

[Katz 78] J.J. Katz, "Effability and Translation", in F. Guenthner and M. Guenthner-Reutter (eds.), Meaning and Translation, Duckworth, London, 1978

[Levý 81] J. Levý, "Übersetzung als Entscheidungsprozeß" in [Wilss 81], 219-235

[Prahl et al. 95] B. Prahl, S. Petzold, S. Heizmann, C. Hauenschild, Variable Analysetiefe und Bewertungskriterien in Verbmobil: Translationswissenschaftliche Grundlagen, Verbmobil-Report 54, Uni Hildesheim, Februar 1995

[Quantz et al. 96] J..J. Quantz, G. Dunker, F. Bergmann, I. Kellner, The FLEX System, KIT Report 124, Technische Universität Berlin, 1996

[Schmitz, Jekat-Rommel 94] B. Schmitz, S. Jekat-Rommel, Eine zyklische Approximation an Sprechhandlungstypen - zur Annotierung von Äußerungen in Dialogen, Verbmobil-Report 28, TU Berlin, September 1994

[Schmitz, Quantz 95] B. Schmitz and J.J. Quantz, "Dialogue-Act Type Recognition in Automatic Dialogue Interpreting", in Proceedings of the The Sixth International Conference on Theoretical and Methodological Issues in Machine Translation (TMI), 1995.

[Sperber, Wilson 86] D. Sperber and D. Wilson, Relevance, Blackwell, Oxford, 1986

[des Tombes, this volume] L. des Tombes, "Compensation", this volume

[Wahlster 93] W. Wahlster, Verbmobil: Übersetzung von Verhandlungsdialogen, Verbmobil Report 1, Saarbrücken, 1993

[Wilson, Sperber 88] D. Wilson and D. Sperber, "Representation and Relevance", in R.M. Kempson (ed.), Mental Representations, Cambridge University Press, Cambridge, 1988, 133-135

[Wilss 81] W. Wilss (ed.), Übersetzungswissenschaft, Wissenschaftliche Buchgesellschaft, Darmstadt, 1981 